\title{
A CONTABILIDADE, AS COOPERATIVAS DE CRÉDITO E A CRISE MUNDIAL
}

\author{
Miriã Rocha Todesco ${ }^{1}$ \\ Patrícia Ferreira Aguiar ${ }^{2}$ \\ Altamiro Lacerda de Almeida Júnior ${ }^{3}$ \\ Jaqueline Aparecida Bayonetta de Souza ${ }^{4}$ \\ Patrícia Margato da Silva Rodrigues
}

\section{RESUMO}

Vivemos um momento de incertezas devido à pandemia de COVID-19. Incertezas que se refletem em aspectos pessoais, mas também na realidade econômica de todo o mundo. Assim, buscou-se entender os impactos preliminares dessa pandemia na rotina do setor contábil de uma cooperativa de crédito. Procurou-se conhecer o funcionamento desse setor e como ele está atuando nesse momento. Este estudo caracteriza-se como um estudo de caso de natureza qualitativa, em que se utilizou como técnica de investigação a pesquisa bibliográfica e a entrevista semiestruturada. A análise de dados se deu a partir da análise de conteúdo. Percebe-se através do estudo que as informações contábeis não servem apenas para fins de legislação, elas são importantes para auxiliar nas estratégias e decisões que visem uma gestão financeira com resultados positivos.

\section{Palavras chave: Contabilidade, Cooperativas de Crédito, Crises}

\section{INTRODUÇÃO}

As incertezas e inseguranças de uma crise econômica afetam todo o mercado. Assim, torna-se importante que todos os setores de uma organização estejam municiados de informações para tomarem decisões mais acertadas. Nesse sentido, o setor contábil possui um papel importante no contexto ao propiciar as informações que subsidiam os gestores das empresas. Dessa forma, busca-se através desse estudo compreender as ações do cotidiano do setor contábil de uma instituição cooperativa de crédito e enfatizou-se a análise das ações nesse momento de pandemia de COVID-19.

\footnotetext{
${ }^{1}$ Graduanda em Ciências Contábeis - Faculdades Integradas de Cataguases - Grupo UNIS; email: Mirian.rochaa18@gmail.com

${ }^{2}$ Graduanda em Ciências Contábeis - Faculdades Integradas de Cataguases - Grupo UNIS; email: Patyferreira8414@gmail.com

${ }^{3}$ Mestre em Administração; Especialista em Marketing e Negócios; Bacharel em Administração;

Professor de graduação nas Faculdades Integradas de Cataguases - Grupo UNIS; Professor nos cursos técnicos no Instituto Federal Sudeste de Minas Gerais - Campus Cataguases; email: altamiro.junior@professor.unis.edu.br

${ }^{4}$ Especialista em Contabilidade Tributária - Faculdade Machado Sobrinho; Bacharel em Ciências Contábeis - Faculdade Sudamérica; Professor FIC/UNIS; email:contab.jaquelinesouza@gmail.com
} 
Para alcançar o objetivo proposto, buscou-se realizar uma pesquisa bibliográfica que subsidiou as análises, além de uma entrevista semiestruturada com a gerente contábil da instituição Sicoob Coopemata, Vanessa Lacerda Alves Fajardo. O estudo possui uma abordagem qualitativa e caracteriza-se como um estudo de caso, exploratório. Utilizouse análise de conteúdo como estratégia para interpretação dos dados coletados na entrevista realizada via web no dia 26/05/2020.

O estudo possui a seguinte estruturação: referencial teórico onde se apresenta os principais conceitos relacionados a contabilidade, a cooperativas de crédito e a crise. Logo após apresenta-se a instituição e entrevista objeto desse estudo. Por fim, estabelecem-se as considerações finais e as referências bibliográficas.

Identificou-se com esse estudo conceitos importantes sobre a contabilidade dentro das organizações e como as cooperativas utilizam as informações extraídas pela contabilidade para a tomada de decisão, dando assim um nível de segurança para a empresa e para seus cooperados; além de entender que a contabilidade não serve apenas para fins de legislação, estando a sua atuação também relacionada a uma visão estratégica e focada em resultados positivos, se tornando uma ferramenta valiosa para gestão financeira.

\section{CONTABILIDADE}

Dantas (2016), relata que o surgimento da contabilidade não seguiu nenhum pensamento filosófico ou qualquer tipo de legislação fiscal; sua evolução se deu pela necessidade prática de se ter uma ferramenta para conhecer e acompanhar o patrimônio. $\mathrm{O}$ autor relata que a contabilidade é uma das ciências mais antigas, há registros que o homem primitivo utilizava pedras e fichas de barro para controlar seu rebanho (DANTAS, 2016).

Matias e Martins (2012) argumentam que os profissionais da contabilidade possuem uma visão privilegiada de uma empresa, pois, dentre suas responsabilidades está o acompanhamento, a execução e controle financeiro, operacional e fiscal da organização. Assim, os contadores podem auxiliar de forma positiva na orientação da condução dos negócios de uma instituição.

Ribeiro (2013) expõe que:

O objetivo da contabilidade é o estudo e o controle do patrimônio e de suas variações visando ao fornecimento de informações que sejam úteis para tomada de decisões. Dentre as informações destacam-se aquelas de natureza econômica e financeira. Naturezas econômicas compreendem, principalmente, os fluxos de receitas e despesas, que geram lucros ou prejuízos, e são responsáveis pela variação do patrimônio líquido. As de natureza financeira abrangem principalmente os fluxos de caixa e do capital de giro (RIBEIRO, 2013, p. 04).

Silva e Antonovz (2015), relatam que a contabilidade possui por objetivo fornecer informações para os tomadores de decisão:

Fornece informações sobre como são compostas as variações do patrimônio e como elas funcionam. É preciso estar atento a quem é o principal usuário das informações e para o que elas serão utilizadas. Atualmente a contabilidade tem duas finalidades básicas: uma ligada ao planejamento, servindo de base para análise situações futuras e a outra o controle do que acontece com a instituição (SILVA E ANTONOVZ. 2015, p. 15). 
De acordo com Dantas e Duarte (2005), a contabilidade vem desempenhando, desde o seu surgimento até os dias atuais, um papel de extrema importância na vida dos indivíduos e da sociedade como um todo. Em sua origem, mesmo sendo realizada de forma rudimentar, a contabilidade era utilizada para auxiliar o homem a manter o controle de suas riquezas e seus excedentes de produção. Com o passar do tempo, a ciência contábil aprimorou-se e tornou-se elementar para a sociedade.

De acordo com Ludícibus (2010), o desenvolvimento inicial do método contábil esteve intimamente associado ao surgimento do capitalismo, como forma quantitativa de mensurar os acréscimos ou decréscimos dos investimentos iniciais alocados a determinadas explorações existentes, sejam elas comerciais ou industriais.

Marion (2009) relata que por meio de relatórios e documentos padronizados, os interessados pelas informações contábeis recordam os fatos acontecidos, analisam os resultados obtidos, e através deles procuram identificar, de maneira aprofundada e global, as causas que levaram aqueles resultados a acontecerem, bem como as decisões a serem tomadas vislumbrando o futuro. Trata-se, portanto, de uma análise global da situação organizacional, fator esse que contribui diretamente para o processo administrativo e estratégico das empresas.

A contabilidade se dá através do registro e controle das operações cotidianas, além da apuração e controle de tais registros. Vendrame (1998) aponta que a contabilidade serve como instrumento de decisão gerencial, acompanhamento de metas e diagnóstico da situação patrimonial apurados a partir do registro dos atos e os fatos econômicos, financeiros e administrativos das aziendas.

Segundo Bach (2017 apud Rios, 2020) indicadores são uma das ferramentas utilizadas pela contabilidade para diagnosticar a situação da empresa, monitorar o desempenho e fornecer insumos para os gestores tomarem decisões. Para Matias (2017 apud Rios, 2020), por meio dos indicadores é possível padronizar o desempenho financeiro entre empresas distintas de maneira confiável, sendo possível verificar o desempenho das empresas avaliadas e compará-lo com outras empresas.

Para Marion (2009) a contabilidade pode ser feita e utilizada por pessoa física ou pessoa jurídica. A contabilidade, portanto, pode ser executada e colocada em prática por um indivíduo (pessoa física), desde que haja necessidade em virtude do volume de negócios que ele possui, assim como por uma organização que possua ou não fins lucrativos (pessoa jurídica). Em sua essência, contudo, a contabilidade é usada por pessoas jurídicas, ou seja, por empresas em geral, que a adota visando conduzir os seus negócios confiavelmente.

Destaca-se que a contabilidade tem aplicação em qualquer organização, seja ela de natureza pública ou privada, independente da sua finalidade, seja ela lucrativa ou não lucrativa, tendo em vista que a contabilidade analisa os padrões comportamentais financeiros de uma organização (RIBEIRO, 2013); (SILVA; ANTONOVZ, 2015).

\section{COOPERATIVAS}

As cooperativas de créditos são organizações financeiras criadas perante as comunidades cooperativas com o objetivo de prestação de serviços financeiros aos associados, entres eles: captações de depósitos à vista e a prazo, cheques, concessão de créditos, prestação de serviços de cobranças e custódia, pagamentos por contas de 
terceiros sob convênio com instituições financeiras públicas e privadas e entre outras operações (PINHEIRA, 2008, p. 92).

Esse tipo de organização é formada por grupo de pessoas de próprias jurisdições e de natureza civil. As cooperativas de créditos são parecidas com os outros bancos, pois contém os mesmos serviços e produtos (ALVES, Dayane Souza de Almeida et al).

Sociedades cooperativas são sociedades de pessoas, com forma e natureza jurídica próprias, constituídas para prestar serviços aos associados, cujo regime jurídico, atualmente, é instituído pela Lei no 5.764, de 16 de dezembro de 1971. As sociedades cooperativas são classificadas como: cooperativas singulares, ou de $1^{\circ}$ grau, quando destinadas a prestar serviços diretamente aos associados; cooperativas centrais e federações de cooperativas, ou de $2^{\circ}$ grau, aquelas constituídas por cooperativas singulares e que objetivam organizar, em comum e em maior escala, os serviços econômicos e assistenciais de interesse das filiadas, integrando e orientando suas atividades, bem como facilitando a utilização recíproca dos serviços; e confederações de cooperativas, ou de $3^{\circ}$ grau, as constituídas por centrais e federações de cooperativas e que têm por objetivo orientar e coordenar as atividades das filiadas, nos casos em que o vulto dos empreendimentos transcender o âmbito de capacidade ou conveniência de atuação das centrais ou federações. (PINHEIRO, 2008, p.7)

Uns dos pontos essenciais das cooperativas de créditos são que elas proporcionam a defesa e o melhoramento da situação econômica dos associados, promovendo baixos custos nos bens e serviços, para que, assim, possam produzir com preços justos para o mercado (FRANKE, 1973, apud SCHARDONG, 2003, p. 81).

Cooperativas de crédito são sociedades de pessoas, constituídas com o objetivo de prestar serviços financeiros aos seus associados, na forma de ajuda mútua, baseada em valores como igualdade, equidade, solidariedade, democracia e responsabilidade social. Além da prestação de serviços comuns, visam diminuir desigualdades sociais, facilitar o acesso aos serviços financeiros, difundir o espírito da cooperação e estimular a união de todos em prol do bemestar comum (PAGNUSSATT, 2004, p. 13).

O século XIX foi marcado por diferentes crises, que marcaram o desenvolvimento das cooperativas de crédito. Após o fim da Segunda Guerra Mundial esse movimento expandiu-se e foi se consolidando até a década de setenta. A expansão do cooperativismo de crédito intensificou a rivalidade entre as instituições financeiras e ganhou notoriedade no cenário nacional (SOUZA, 1992).

As cooperativas no Brasil são representadas pela Organização das Cooperativas Brasileiras (OCB), criado em 1969 durante o IV congresso brasileiro de cooperativismo em Belo Horizonte, sendo responsável por fomentar e defender o sistema cooperativista no país, atuando junto aos poderes, Executivo, Legislativo e Judiciário em busca de avanços para o setor (OCB, 2019). O ramo de crédito no Brasil, no final de 2018 contabilizou 909 cooperativas de crédito registradas, 9.840.977 cooperados e geram 67.267 empregos diretos em todo território nacional. Nos últimos cinco anos apresentou uma queda de 7,24\% no número de cooperativas, em contrapartida, cresceu $42 \%$ em número de associados (...) o estado de São Paulo representa $23,8 \%$ do total das cooperativas de crédito singulares ativas, seguido por Minas Gerais com $21,5 \%$, juntas contabilizam $45,3 \%$ das cooperativas singulares de crédito de todo país (OCB, 2018). Em 2018 no estado de Minas Gerais tinham 771 cooperativas registradas, sendo 184 cooperativas registradas neste ano, 1,74 milhão de cooperados e 43,4 mil empregos diretos. A movimentação econômica foi de R \$ 53,6 bilhões, representando 9\% do PIB do estado e a contribuição para os cofres públicos foi R $\$ 1,7$ bilhões em tributos. (RIOS, et.al, 2020). 
Os bancos cooperativos funcionam sem restrições ou privilégios, competindo diretamente com os bancos comerciais e com o sistema de caixas econômicas, pertencentes aos municípios. (Borges, Benedicto \& Carvalho, 2014 apud Rios,2020). Atrelado a isso, apesar das cooperativas de crédito serem organizações sem fins lucrativos, seu caráter de sociedade civil que apresenta fins econômicos faz necessário que seu desempenho seja medido de maneira distinta das instituições de crédito convencionais, pois sua perenidade no mercado se dá por intermédio da prestação adequada de serviços a seus cooperados (Borges, Benedicto\& Carvalho, 2014 apud Rios,2020).

Maia (2012) relata que o foco principal de uma cooperativa financeira é o fornecimento de crédito sob a forma de empréstimos pessoais ou para finalidades específicas, com taxas e juros mais baratos e com menor burocracia. Se comparada a outras instituições financeiras as cooperativas de crédito representam um instrumento de inclusão de pequenos empreendimentos no sistema financeiro, além de serem uma alternativa de prestação de serviços financeiros aos cidadãos com menores possibilidades de acesso à rede bancária tradicional e a comunidades desprovidas de infraestrutura bancária. (MAIA, 2012)

Conforme demonstram Francisco et al. (2009 apud Maia, 2012), essas instituições financeiras são capazes de reduzir a transferência de recursos de municípios menores para os grandes centros, na medida em que reciclam os recursos captados devolvendo-os em forma de crédito aos agentes das regiões geográficas onde estão instaladas, ao contrário dos grandes conglomerados financeiros com presença nacional, que contribuem para a concentração de recursos nos grandes centros.

\section{CRISES}

De acordo com o National Bureau of Economic Research (NBER) de Massachusetts, um ciclo econômico consiste em quatro fases: pico, expansão, recessão e recuperação. O pico é o ponto mais alto de todas as fases do ciclo econômico. Nele a taxa de desemprego atinge o nível mínimo. Marca também o final da expansão e o início da recessão; na expansão ocorre a inversão de sentido de descendente para ascendente, quando o crescimento ultrapassa a tendência; durante a recessão, ocorre uma queda significativa da atividade econômica que se espalha pela economia e pode durar de alguns meses a alguns anos; e a recuperação ocorre também na fase ascendente, mas o crescimento fica abaixo da tendência (OLIVEIRA, et.al, 2014). As métricas utilizadas para a aferição da atividade econômica são as mais diversas, como Produto Interno Bruto (PIB), nível de emprego e renda, entre outros indicadores (STEFANI, et. al, 2019).

Uma crise econômica pode ser generalizada, instabilizando assim toda a economia mundial. As crises econômicas além de afetarem a produção, a comercialização e o consumo, elas geram incertezas e inseguranças ocasionando a procura apenas por itens de necessidades básicas (REIS e COSTA,2009). De acordo com os estudos de Graham e King (2000), Ho et al. (2001), Davis-Friday e Gordon (2005) e, Davis-Friday et al. (2006) citados por Reis e Costa (2009), as crises econômicas podem resultar em problemas no mercado monetário proporcionando uma desvalorização da moeda doméstica e ainda no mercado de capitais promovendo um declínio do preço das ações.

Nogueira (2011) diz que a crise econômica, também chamada de recessão, resulta entre outras coisas na diminuição do PIB - Produto Interno Bruto. Geralmente segundo o 
autor, as crises impactam negativamente as empresas ocasionando a diminuição do lucro e demissões. Além disso, para o autor, a crise faz com que as famílias diminuam seus investimentos e consumo. Nesse sentido, a crise pode ocasionar um efeito dominó (NOGUEIRA, 2011).

Pinheiro et al. (2018) argumenta que sobretudo em momentos de crise, a gestão financeira eficiente é necessária e indispensável para que se torne mais fácil lidar com o dia a dia nos períodos de recessão. Sem o gerenciamento adequado, diversas situações podem ser prejudiciais para o negócio, tanto as internas quanto as externas.

\section{ESTUDO DE CASO:}

O Sicoob Coopemata é uma cooperativa de crédito que tem a ideologia cooperativista como base filosófica. Seu principal objetivo é facilitar a vida do cooperado, prestando serviços financeiros sustentáveis, de qualidade e com eficiência. Um dos diferenciais do cooperativismo de crédito é que os cooperados são donos e usuários do seu próprio negócio e o resultado financeiro é revertido em benefício aos mesmos e em benefício da comunidade onde estão inseridos.

A constituição do Sicoob Coopemata se deu a partir de uma visita realizada por um grupo de empresários a uma cooperativa de crédito do estado do Espírito Santo, que deslumbrados com a experiência, decidiram então importar aquele modelo de instituição financeira, sem fins lucrativos, para o município de Cataguases e cidades circunvizinhas.

O Sicoob Coopemata teve sua inauguração em agosto de 1998, inicialmente com 22 associados. Passados 20 anos, continua a disseminar sua filosofia cooperativista e fomentar a atividade produtiva na região da Zona da Mata, Campos das Vertentes, a Capital Mineira e a sua Mesorregião.

A adesão da cooperativa à marca SICOOB se efetivou através da homologação pelo Banco Central do Brasil, na Assembleia Geral Extraordinária (AGE) realizada em 2008.

O Sicoob Coopemata busca ser a principal e mais completa instituição financeira para os seus cooperados, com um trabalho eficaz e transparente. Oferece um atendimento personalizado aos seus cooperados, além de participá-los da distribuição das sobras e do acesso à todas informações financeiras e econômicas da instituição.

Percebe-se através da entrevista realizada com a gerente contábil da instituição, que a empresa mantém um setor contábil próprio para realizar a contabilidade. Esse departamento além de processar os números, transformando-os em dados contábeis, fornece relatórios para auxiliar a gestão da organização com informações financeiras e econômicas.

Verificou-se que a instituição utiliza as informações contábeis para desenvolver seu planejamento estratégico através do seguinte processo: a contabilidade reúne todos os números e dados da cooperativa como um todo e também por ponto de atendimento, analisa o histórico desses números e dados para propor ações de acordo com a expectativa do mercado, e faz o acompanhando dos indicadores financeiros, de liquidez e de resultado. Os dados contábeis fornecidos são utilizados para subsidiar a tomada de decisões e fazer projeções para o futuro da cooperativa. 
De acordo com a entrevistada além das informações contábeis, que são de extrema importância para a tomada de decisões, por se tratar de instituição financeira, outras informações também são necessárias. Torna-se importante conhecer o cenário atual de todos os ramos de empresas com a qual a cooperativa trabalha para que as decisões possam ser tomadas e/ou planejadas de forma mais assertiva.

Apurou-se que entre as principais ferramentas contábeis utilizadas para tomada de decisão na Coopemata estão: I - Análise de custos, que serve para conhecer a realidade de custos vivenciada e trabalhar na melhoria ou otimização desses custos; II - Análise gerencial, que tem como objetivo auxiliar na tomada de decisões, podendo identificar, analisar e interpretar informações importantes; e III - Sistema de informações contábeis utilizado, que dispõe de informações importantes e agrupadas por determinados critérios para que possam ser analisadas por determinados grupos ou momentos de maiores interesses ou necessidades.

Identificou-se que a cooperativa busca apresentar suas informações aos dirigentes e cooperados rotineiramente. Algumas informações são disponibilizadas diariamente, outras semanalmente e algumas mensalmente. Para a entrevistada é importante que os interessados acompanhem os números da cooperativa. Além dessas informações para os principais interessados, a cooperativa por força de lei disponibiliza semestralmente suas informações em jornais de circulação regional e no próprio site. Os dirigentes recebem as informações através dos sistemas internos, e-mail e reuniões. Já os cooperados são informados através do site, de informes corporativos, pré assembleias e assembleias.

Percebeu-se que embora o país esteja passando por um momento ímpar em relação a crise da saúde e da economia, a cooperativa está reagindo positivamente a essas adversidades. A Coopemata utilizou alguns benefícios disponibilizados pelo governo para auxiliar as empresas a se manterem financeiramente estáveis enquanto durar o período de crise, como antecipação de férias e suspensão do contrato de trabalho para alguns cargos/áreas, tendo em vista que no início da crise, a demanda de alguns setores internos diminuiu, principalmente pelas incertezas vividas pelos cooperados. A cooperativa espera retornar suas atividades normais em pouco tempo.

Inicialmente a instituição adotou o trabalho home office para diversos setores, e isso trouxe novas adequações, principalmente no que tange às reuniões, que agora são realizadas por vídeo conferência. As atividades em alguns Pontos de Atendimento (PA) sofreram alterações, devido as exigências impostas por algumas prefeituras. Esse fato trouxe a necessidade de adequação dos gerentes para continuar atendendo seus clientes. A utilização das plataformas digitais está contribuindo para manter a proximidade dos funcionários da cooperativa com os cooperados.

O setor contábil, nesse momento de crise, está atuando mais do que nunca como um consultor, auxiliando com informações mais precisas e tempestivas para a tomada de decisão. "É importante que a instituição atravesse este momento com segurança", afirmou a entrevistada que completou: "a cooperativa possui uma área de pessoas e de negócios preparada e capacitada, e as áreas atuam independente, mas com bastante harmonia”.

O Sicoob Coopemata está mobilizado para auxiliar seus cooperados nesse momento de crise. Algumas ações como prorrogação das operações de crédito, empréstimos com taxas diferenciadas, consultoria online com os gerentes, estão sendo praticadas constantemente. De acordo com a entrevistada os gerentes de negócios e gerentes regionais estão indo além das demandas dos cooperados, buscando prestar consultorias individuais. 
Para Vanessa o Sicoob Coopemata, "agora mais do que nunca (...) espera continuar atendendo da melhor maneira para que possa sair da pandemia mais fortalecidos, reafirmando seu lema: "Cooperado forte, cooperativa forte".

\section{CONSIDERAÇOES FINAIS}

Acredita-se que os resultados obtidos nesse estudo possam auxiliar para o conhecimento da área da contábil e para o setor das cooperativas de crédito.

Diferentemente dos bancos as cooperativas são organizações financeiras criadas por sócios para prestação de serviços financeiros aos seus clientes. Através de suas ações elas buscam diminuir as desigualdades sociais, facilitando o acesso a serviços financeiros e de crédito.

Tanto para as cooperativas de crédito como para outras instituições, o setor contábil é responsável por fornecer informações que possam subsidiar a tomada de decisões, contribuindo assim para que as organizações possam atingir seus objetivos financeiros, econômicos e patrimoniais.

Percebeu-se que a Pandemia de COVID-19 afetou diretamente a rotina das empresas, assim como a rotina do Sicoob Coopemata. Contudo, mesmo diante da instabilidade ocasionada pelo contexto de crise sanitária e econômica, verificou-se que o setor contábil adaptou sua rotina às necessidades criadas pela crise e manteve a qualidade na entrega de resultados e informações, contribuindo de forma positiva para auxiliar à cooperativa a tomar as decisões inerentes ao momento.

\section{REFERÊNCIAS}

ALVES, Dayane Souza de Almeida; ALVES, Ivan; SILVA, Patrícia Vaz da Costa. Pespectiva do associado sobre a tecnologia utilizada pela cooperativa sicredi. Disponível em: $<$ https://repositorio.ifgoiano.edu.br/bitstream/prefix/473/1/TC\%20Patricia\%20e\%20 Dayane\%20Souza.pdf $>$. Acesso em: 19 abr.2020.

BACH. Indicadores de desempenho: Percepção de dirigentes das cooperativas mineiras sobre o Sistema PEARLS. Disponível em: $<$ https://unihorizontes.br/wpcontent/uploads/2020/04/Artigo.pdf >. Acesso em:24 maio.2020.

BORGES, BENEDICTO \& CARVALHO. Indicadores de desempenho: Percepção de dirigentes das cooperativas mineiras sobre o Sistema PEARLS. Disponível $\mathrm{em}:<$ https://unihorizontes.br/wp-content/uploads/2020/04/Artigo.pdf $>$. Acesso em:24 maio.2020.

DANTAS MACIEL. ACKERMANN, Felipe. Introdução as criptomoedas: Uma análise de possíveis impactos na economia, investimentos e contabilidade. Curso de ciências contábeis, $\quad\left[\begin{array}{lll}s . & l\end{array}\right], \quad 2018 . \quad$ Disponível em: 
<https://repositorio.ucs.br/xmlui/bitstream/handle/11338/4314/TCC\%20Felipe\%20Ack ermann\%20Maciel.pdf?sequence=1\&isAllowed=y>. Acesso em: 19 abr. 2020.

DANTAS E DUARTE.CASAGRANDE, Diego José .A importância da contabilidade como ferramenta gerencial nos processos estratégicos e decisórios das organizações. 2018 Disponível em: <https://simtec.fatectq.edu.br/index.php/simtec/article/view/249/237>.Acesso em : 20 maio. 2020.

FRANCISCO et al. .Gerenciamento de resultados em cooperativas de crédito no brasil. 2012 disponível em: $<$ https://repositorio.ufmg.br/bitstream/1843/BUOS98DH2H/1/dissertacao___saulo_ cardoso_maia_final.pdf $>$. Acesso em:24 maio 2020.

FRANKE, apud SCHARDONG,.SCHIMMELFENIG, Cristiano. Cooperativismo de crédito: Uma tendência. Vol.5 - n.10 - Janeiro - Junho 2010. Disponível em: <https://www.bage.ideau.com.br/wpcontent/files_mf/4d4d0fc34b02f107358a0ce5f14df c0b84_1.pdf $>$. Acesso em: 23 abr.2020.

LUDÍCIBUS, CASAGRANDE, Diego José. A importância da contabilidade como ferramenta gerencial nos processos estratégicos e decisórios das organizações. 2018. disponível em:<https://simtec.fatectq.edu.br/index.php/simtec/article/view/249/237>. Acesso em: 20 maio.2020.

NATIONAL BUREAU OF ECONOMIC RESEARCH. Disponível em: http://www. nber.org/cycles/recessions.html. Acesso em: 16 ago. 2018.

MAIA, Saulo Cardoso. Gerenciamento de resultados em cooperativas de crédito no brasil. 2012 disponível em: <https://repositorio.ufmg.br/bitstream/1843/BUOS98DH2H/1/dissertacao saulo_card oso_maia_final.pdf $>$. Acesso em: 24 maio 2020.

MARION CASAGRANDE, Diego José. A importância da contabilidade como ferramenta gerencial nos processos estratégicos e decisórios das organizações. 2018. Disponível em: <https://simtec.fatectq.edu.br/index.php/simtec/article/view/249/237>. Acesso em: 20 maio.2020.

MARION CASAGRANDE, Diego José. A importância da contabilidade como ferramenta gerencial nos processos estratégicos e decisórios das organizações. 2018. Disponível em: $\langle$ https://simtec.fatectq.edu.br/index.php/simtec/article/view/249/237>. Acessoem: 20 maio.2020. 
MATIAS E MARTINS. CARDOSO, Larise Lopes; BERNARDO, Whendeo da Silva; MOREIRA, Marcia Athayde. Elementos de contribuição da contabilidade para a sobrevivência de micro e pequenas empresas. 2019.Disponível $\mathrm{em}:\langle$ http://revista.isaebrasil.com.br/index.php/EGS/article/view/39/33>. Acesso em: 19 maio.2020.

MATIAS. Indicadores de desempenho: percepção de dirigentes das cooperativas mineiras sobre o Sistema PEARLS. Disponível em: $<$ https://unihorizontes.br/wpcontent/uploads/2020/04/Artigo.pdf $>$. Acesso em:24 maio.2020.

NOGUEIRA. AMORIM, Bruna Ellen Alves. Demonstração das mutações do patrimônio líquido: Uma análise dos reflexos da crise na política de distribuição de lucro das companhias listadas na b3. 2019. Disponível em: $<$ http://pensaracademico.facig.edu.br/index.php/repositoriotcc/article/view/1799/14 22>. Acesso em: 19 maio. 2020.

O SICOOB COOPEMATA, 2020 Disponível em:

$<$ https://sicoobcoopemata.com.br/institucional/cooperativa/nossa-

historia\#: :text=0\%20Sicoob\%20Coopemata\%20\%C3\%A9\%20uma,ideologia\%20coo perativista $\% 20$ como $\% 20$ base $\% 20$ filos $\% \mathrm{C} 3 \% \mathrm{~B} 3$ fica. \&text=Assim $\% 2 \mathrm{C} \% 20$ inaugurado $\% 20 \mathrm{em} \% 2024 \% 20 \mathrm{de}, \mathrm{de} \% 20 \mathrm{cr} \% \mathrm{C} 3 \%$ A9dito $\% 20 \mathrm{e} \% 20 \mathrm{seus} \% 20 \mathrm{valores}>$. Acesso em: 4 junho 2020.

OLIVEIRA, Lígia; BASTOS, Liliana; ANDRADE, Miguel. Crise, Ciclos e Crescimento. Economia, $[s . \quad l$.$] , 2014/2015. Disponível em:$ <https://www.academia.edu/11330676/Crise_Ciclos_e_Crescimento>. Acesso em: 12 maio 2020.

PAGNUSSATT,.SCHIMMELFENIG, Cristiano. Cooperativismo de crédito: Uma tendência. Vol.5 - n.10 - Janeiro - Junho 2010. Disponível em: $<$ https://www.bage.ideau.com.br/wpcontent/files_mf/4d4d0fc34b02f107358a0ce5f14df c0b84_1.pdf>. Acesso em: 23 abr.2020.

PINHEIRA,. ALVES, Ivan; SILVA, Patrícia Vaz da Costa. Perspectiva do associado sobre a tecnologia utilizada pela cooperativa sicredi. Disponível em: $<$ https://repositorio.ifgoiano.edu.br/bitstream/prefix/473/1/TC\%20Patricia\%20e\%20 Dayane\%20Souza.pdf $>$. Acesso em: 19 abr.2020.

PINHEIRO ET AL. AMORIM, Bruna Ellen Alves. Demonstração das mutações do patrimônio líquido: Uma análise dos reflexos da crise na política de distribuição de lucro das companhias listadas na b3. 2019. Disponível em: $<$ http://pensaracademico.facig.edu.br/index.php/repositoriotcc/article/view/1799/14 22>. Acesso em: 19 maio. 2020. 
PINHEIRO, p.7. Marcos Antônio Henriques. Cooperativas de crédito história da evolução normativa no brasil. 2008. Disponível em: $<$ https://www.uniprimesulms.com.br/upload/file/pagina/anexo_8_file1_cooperativasde-crdito-histria-da-evoluo-normativa-no-brasil.pdf $>$. Acesso em: 23 maio. 2020.

REIS e COSTA, Danilo José Santana; COSTA, Fábio Moraes. A relevância da informação contábil em período de crises macroeconômicas. Disponível em: <http://legado.fucape.br/_public/producao_cientifica/2/Reis\%20-

\%20A\%20relev\%C3\%A2ncia\%20da\%20informacao.pdf>. Acesso em 21 maio.2020.

RIBEIRO. SILVEIRA, Maycon Antônio Quinzani da et al. Análise financeira: Um estudo de caso em uma empresa do setor de móveis e eletrodomésticos do município de Juína-MT. Revista científica da ajes, [s. l.], v. 08, ed. 17, Julho/Dezembro 2019. Disponível em: <http://www.revista.ajes.edu.br/index.php/rca/article/view/319/259. Acesso em: 19 abr. 2020.

RIBEIRO; SILVA; ANTONOVZ.SILVEIRA, Maycon Antônio Quinzani da et al. Análise financeira: Um estudo de caso em uma empresa do setor de móveis e eletrodomésticos do município de Juína-MT. Revista científica da ajes, [s. l.], v. 08, ed. 17, Julho/Dezembro $2019 . \quad$ Disponível em: <http://www.revista.ajes.edu.br/index.php/rca/article/view/319/259>. Acesso em: 19 abr. 2020.

Rios, et.al, Indicadores de desempenho: Percepção de dirigentes das cooperativas mineiras sobre o Sistema PEARLS. Disponível em: $<$ https://unihorizontes.br/wpcontent/uploads/2020/04/Artigo.pdf >. Acesso em:24 maio.2020.

SILVA E ANTONOVZ, p.15. SILVEIRA, Maycon Antônio Quinzani da et al. Análise financeira: um estudo de caso em uma empresa do setor de móveis e eletrodomésticos do município de Juína-MT. Revista científica da ajes, [s. l.], v. 08, ed. 17, Julho/Dezembro 2019. Disponível em:

<http://www.revista.ajes.edu.br/index.php/rca/article/view/319/259>. Acesso em: 19 abr. 2020.

STEFANI, et. Al. Crises econômicas e a relevância da informação contábil. .Disponível em: $\langle$ http://editorarevistas.mackenzie.br/index.php/pcg/article/view/12328/7720>. Acesso em :20 maio.2020.

SOUZA, Alzira Silva. Cooperativismo de crédito: Realidades e perspectivas. Disponível em: <http://www.sicoobcecremef.com.br/downloads/cooperativismo_credito_realidade_pers pectiva.pdf $>$. Acesso em: 23 maio 2020 
VENDRAME. ALMEIDA, Maria Somália Teixeira de. A aplicabilidade da contabilidade gerencial na tomada de decisão. Trabalho profissional (Ciências Contábeis) - PONTIFÍCIA UNIVERSIDADE CATÓLICA DE MINAS GERAIS, Belo Horizonte, 2007.2 Disponível em: <http://sinescontabil.com.br/monografias/trab_profissionais/araceli.htm>. Acesso em: 28 abr. 2020. 